\title{
Inovação, desenvolvimento e transferência de tecnologia em universidade clássica e tecnológica: comparação entre UFABC e UTFPR
}

\author{
Innovation, development, and transfer of technology in a classical
}

and in a technological university: a comparison between UFABC and UTFPR

\author{
Agnaldo da Costa ${ }^{1}$ \\ Luiz Alberto Pilatti ${ }^{2}$ \\ Celso Bilynkievycz Santos ${ }^{3}$
}

Resumo: O objetivo deste estudo é comparar duas importantes jovens universidades do Brasil, uma clássica, a Universidade Federal do ABC (UFABC), e outra tecnológica, a Universidade Tecnológica Federal do Paraná (UTFPR), considerando dois eixos definidos pela Rede das Universidades Tecnológicas e Politécnicas da América Latina e do Caribe (RUTyP), a inovação e o desenvolvimento e a transferência de tecnologia. O estudo é comparativo e de natureza exploratória, constituído por informações de 3.210 currículos disponíveis na Plataforma Lattes de pesquisadores das duas instituições de ensino superior, dos quais foram extraídos 1.573 registros relacionados à inovação (patentes, softwares e cartas, marcas e similares) e informações das patentes registradas na Agência de Inovação Tecnológica (AGINT) e no Instituto Nacional de Propriedade Intelectual (INPI). Os dados foram analisados por meio de técnicas de estatística descritiva. Constatou-se que, em pouco mais de uma década de existência das duas instituições analisadas, houve poucas transferências de tecnologia para o setor produtivo, e um distanciamento do modelo de universidade tecnológica pela UTFPR. Conclui-se que a UTFPR e a UFABC apresentam muita similaridade apesar dos modelos distintos.

Palavras-chave: Universidades clássicas. Universidades tecnológicas. Patentes. Inovação. 
Abstract: The objective of this study is to compare two important young universities in Brazil, one classic, the Federal University of ABC (UFABC), and the other technological, the Federal Technological University of Paraná (UTFPR), considering two axes defined by the Network of Technological and Polytechnic Universities Latin America and the Caribbean (RUTyP), innovation and the development and transfer of technology. The study is comparative and exploratory in nature, consisting of information from 3,210 curricula available on the Lattes Platform of researchers from the two higher education institutions, from which 1,573 records related to innovation were extracted (patents, software and letters, brands, and the like) and information of patents registered with the Agency for Technological Innovation (AGINT) and the National Institute of Intellectual Property (INPI). The data were analyzed using descriptive statistics techniques. It was found that, in just over a decade of existence of the two institutions analyzed, there were few transfers of technology to the productive sector, and a departure from the model of technological university by UTFPR. It is concluded that UTFPR and UFABC show a lot of similarity despite the different models.

Keywords: Classical universities. Technological universities. Patents. Innovation.

${ }^{1}$ Universidade Tecnológica Federal do Paraná | Programa de Pós-Graduação em Ensino de Ciência e Tecnologia | Ponta Grossa | Paraná | Brasil. Contato: agnaldocosta@utfpr.edu.br. ORCID: https://orcid.org/0000-0002-9955-2854

${ }^{2}$ Universidade Tecnológica Federal do Paraná | Programa de Pós-Graduação em Ensino de Ciência e Tecnologia | Ponta Grossa | Paraná | Brasil. Contato: lapilatti@utfpr.edu.br. ORCID: https://orcid.org/0000-0003-2679-9191

${ }^{3}$ Universidade Estadual de Ponta Grossa | Ponta Grossa | Paraná | Brasil. Contato: bilynkievycz@uepg.br. ORCID: https://orcid.org/0000-0003-2107-8299

- Recebido em: 19 de julho de 2019

- Aprovado em: 27 de abril de 2021

DOI: http://dx.doi.org/10.1590/S1414-40772021000200002

Este é um artigo publicado em acesso aberto sob uma licença Creative Commons

https://creativecommons.org/licenses/by-nc/4.0/ 


\section{Introdução}

A competição por novos mercados, no atual processo de globalização, tem estimulado os países a criarem mecanismos de fortalecimento dos seus sistemas nacionais de ciência, tecnologia e inovação (CT\&I). O objetivo implícito neste movimento é o de facilitar a integração de ações de inovação, de cooperação e de transferência de tecnologia. No contexto brasileiro, o governo federal tem sistematicamente incentivado ações de inovação por meio de financiamento de projetos, visando à interação entre os setores público e privado, para impulsionar a transferência de tecnologia.

O processo é cingido de elevada complexidade e, nele, a universidade tem papel distinto. As universidades são produtoras de conhecimento e formadoras de mentes que contribuem na construção de um país melhor (BRITO CRUZ, 2010). No século IX, o foco do ensino e da formação acadêmica era na formação generalista, em torno de um conjunto de cursos. Com a revolução industrial, no final do século XVIII e século XIX, o ensino e a pesquisa foram fortemente impactados pelas demandas da sociedade. A produção do conhecimento e seu uso, realizado dentro dos muros destas instituições quase milenares, extrapolaram este limite estreito com a realidade que se conformou.

No Brasil, importantes avanços convergem com o movimento planetário. A aprovação da Lei de Inovação, em dezembro de 2004, que incentiva a criação dos Núcleos de Inovação Tecnológica (NITs) nas instituições de ensino superior, com objetivo de estimular tais parcerias é um dos avanços notórios. No ano de 2005, foi criada a única universidade tecnológica (UT) do Brasil, pela Lei n. ${ }^{\circ}$ 11.184, que transformou o Centro Federal de Educação Tecnológica do Paraná (CEFET-PR) em Universidade Tecnológica Federal do Paraná (UTFPR) (BRASIL, 2005b). A transformação em UT não ocorreu por política de Estado, e sim, por iniciativa da instituição, induzida por mudanças impostas ao cenário educacional brasileiro, as quais iniciaram em 1996, com a Lei n. ${ }^{\circ}$ 9.394, de Diretrizes e Bases da Educação Nacional (LDB) (BRASIL, 2005c), e, no ano seguinte, com o Decreto n. ${ }^{\circ}$ 2.208/97 (BRASIL, 1997), que alteraram o percurso do ensino profissional no país, inviabilizando o modelo de cursos técnicos oferecidos pelo CEFET-PR.

Como uma UT, a UTFPR tem, prioridade, na capacitação e na formação de profissionais para a indústria e para as áreas de tecnologia (UNIVERSIDADE TECNOLÓGICA FEDERAL DO PARANÁ, 2007). Seu diferencial em relação ao modelo clássico de universidade é a ênfase no relacionamento com o setor produtivo, a proximidade com o uso da ciência e com problemas reais. Atualmente, a UTFPR possui 13 campi, com cursos nas áreas de engenharia, tecnologia 
e licenciatura. Seu corpo docente é composto por 2.549 professores, desses, 1.730 são doutores. Apesar da diversidade de cursos, a UTFPR é a instituições pública de ensino superior (IES) que apresenta a maior oferta de vagas em cursos de engenharia no país.

Dentro do modelo clássico, foi criada pela Lei n. ${ }^{\circ}$ 11.145, de 26 de julho de 2005 (BRASIL, 2005a), a Universidade Federal do ABC (UFABC), que nasceu com orientação para a inovação e tem como destaque a produção acadêmica por meio do conhecimento interdisciplinar. A UFABC foi pioneira na implementação de bacharelados interdisciplinares no ensino público federal no Brasil, rejeitando a ideia de organização da universidade em departamentos acadêmicos (ALMEIDA; ERNICA, 2015; BARREYRO; AURELIANO, 2010). Nos últimos anos, seus resultados a colocam como uma das maiores universidades de pesquisa da América Latina. É a única universidade do Brasil que possui somente pesquisadores com doutorado, totalizando 670 docentes. Seus cursos são nas áreas de engenharia, ciências exatas e da terra e licenciatura; distribuídos em dois campi, Santo André e São Bernardo do Campo.

A escolha da tecnológica UTFPR e da clássica UFABC para comparação advém dos resultados alcançados pelas duas instituições nos rankings acadêmicos nacionais e internacionais que avaliam IES, utilizando de uma série de critérios.

Nesse contexto, a UFABC foi classificada pelo ranking Times Higher Education (THE), em 2018, como a 34 ${ }^{\mathrm{a}}$ melhor universidade da América Latina e, em 2018, destacou-se na 37 posição geral no Ranking Universitário Folha (RUF), que classifica apenas universidades brasileiras (RANKING..., 2018). O RUF, no critério internacionalização, classifica a UFABC em primeiro lugar entre as universidades brasileiras quanto às suas publicações na área científica com fator de impacto (FI) acima da média mundial (CAPELLE, 2016).

A UTFPR aparece no RUF de 2018 ocupando a 55 $5^{\text {a }}$ posição na classificação geral do ranking. No The World University Rankings (2018), no THE, a UTFPR é a 26. ${ }^{a}$ colocada entre as universidades brasileiras e a $19^{\mathrm{a}}$ entre as federais.

As duas IES pesquisadas têm em comum o ano da criação (2005). A UFABC representa o modelo de universidade clássica, com o conceito de transmissão do saber baseado no tratado de Bolonha. Com as revoluções que ocorreram na Europa e uma nova visão a respeito de ciência, em 1810, o educador e reformador alemão Wilhelm von Humboldt (1767-1835) lançou as bases da universidade clássica. A filosofia de Humboldt busca unidade entre ensino e pesquisa e a verdade, por meio da ciência (CUNHA, 1982). Ainda, é antagônica às concepções adotadas pela política universitária voltada para a formação profissional criada pela Revolução Reformadora de Napoleão, em 1789 (CUNHA, 1982; SILVEIRA; BIANCHETTI, 2016). 
Contrapondo as concepções humboldtianas e napoleônicas, as universidades do final do século XX criaram mecanismos desenvolvimentistas que privilegiaram as políticas de ciência e tecnologia (SILVEIRA; BIANCHETTI, 2016). Etzkowitz e Zhou (2017) destacam que, na década de 1990, as universidades adquiriram novas funções, além do ensino e da pesquisa, devido à sua participação mais efetiva no desenvolvimento econômico.

Segundo Silva e Kovaleski (2009), um dos motivos dessa mudança está na formação que as universidades clássicas (UCs) preconizaram, caracterizada pela investigação científica, sem necessariamente estar ligada a projetos e parcerias com o setor produtivo. As revoluções ocorridas produziram a demanda qualificada da formação de recursos humanos nas áreas técnicas para sustentar o desenvolvimento tecnológico. Diferente das universidades clássicas, de história quase milenar, as universidades tecnológicas são um produto da revolução, e surgiram na Europa do século XVIII (PILATTI; LIEVORE, 2018).

Outro fator que incentivou a formação técnica foi a aproximação da universidade com os setores empresariais, aliada às mudanças ocorridas na economia no século XXI, que mudou o pensamento dos educadores sobre a formação do profissional (DELORS et al., 2010).

Em 2014, foi criada a Rede de Universidades e Institutos Politênicos da América Latina e do Caribe (RUTyP), com filiação de 17 instituições de várias regiões geográficas, divididas entre México, América Central, América do Sul e Caribe, a qual tem como objetivo o desenvolvimento tecnológico e científico para integração de uma rede de cooperação técnica nas áreas de ensino, pesquisa e extensão; boas práticas de gestão; qualidade acadêmica; e, comprometimento com as questões sociais e ambientais (PILATTI; LIEVORE, 2017).

As redes de universidades tornaram-se norteadoras de ações institucionalizadas e legítimas, que buscam a organização educacional, interagindo, compartilhando ideias, em função de um objetivo comum. Assim, a RUTyP definiu seis eixos tecnológicos que devem caracterizar uma UT: empreendedorismo; inovação; pesquisa, desenvolvimento e transferência de tecnologia; parques tecnológicos e cidades do conhecimento; responsabilidade social e ambiental; e, ligação com os setores produtivos (PILATTI; LIEVORE, 2017).

Passada mais uma década de sua criação, a identidade tecnológica da UTFPR ainda está em construção. A UFABC nasceu com um modelo mais estruturado. A comparação com base em eixos estruturantes de UTs permite a compreensão da aderência ao modelo. Assim, o presente estudo tem como objetivo comparar duas importantes jovens universidades brasileiras, uma clássica, a UFABC, e, outra tecnológica, a UTFPR, considerando dois eixos definidos pela RUTyP, a inovação e o desenvolvimento e transferência de tecnologia. 


\section{Metodologia}

Para a extração dos dados dos currículos Lattes dos docentes das duas IES, utilizou-se o software Stela Experta, ferramenta de gestão acadêmica de acesso restrito, integrada à Plataforma Lattes, que fornece uma variedade de análise e extração de dados em planilhas do MSExcel (xls). A extração de dados da Plataforma Lattes para análise foi realizada entre os meses de maio e julho de 2018. Há $90 \%$ dos dados atualizados para a clássica UFABC e $84 \%$ dos dados para a tecnológica UTFPR.

A base de dados montada para análise das patentes cadastradas no currículo Lattes dos pesquisadores das IES pesquisadas tem por objetivos:

a) aferir as diferenças entre as patentes que foram cadastradas e as patentes de invenção submetidas ao INPI;

b) acurar as diferenças das patentes cadastradas na Plataforma Lattes entre as IES;

c) verificar a quantidade de patentes desenvolvidas e transferidas para o setor produtivo.

Cardoso e Machado (2008) enfatizam que a Plataforma Lattes permite o cadastramento das produções científicas dos pesquisadores, assim, torna-se um dos mais importantes memoriais de gestão organizacional, quando se trata de produções técnico-científicas no Brasil.

Em seu banco de dados, é possível encontrar mais de 3.6000.000 currículos de estudantes, docentes e pesquisadores das mais diversas áreas do conhecimento. Recentemente, a Plataforma Lattes foi citada na revista Nature, como um exemplo de banco de dados (LANE, 2010).

Os registros foram recuperados a partir das listas de docentes disponíveis nos sítios das universidades pesquisadas. A Tabela 1 apresenta a quantidade de dados extraídos e exportados para planilha do Excel.

Tabela 1 - Tipos de patentes encontrados no currículo lattes dos pesquisadores da UTFPR e da UFABC

\begin{tabular}{ccc}
\hline Tipos de patentes & UTFPR & UFABC \\
\hline Softwares & 1464 & 195 \\
Patentes de invenção & 523 & 153 \\
Cartas, mapas e similares & 23 & 8 \\
\hline
\end{tabular}

Fonte: Autoria própria.

Com os arquivos em formato xls, iniciou-se o pré-processamento dos dados, que envolve a criação e o enriquecimento da base de dados, a seleção, a exploração, a limpeza dos registros, que foram convertidos para formato comma separated values (CVS) e utilizados 
como base para as análises estatísticas no software R (Figura 1). O R é um ambiente de software livre para computação estatística e gráfica, que pode ser executado em várias plataformas, como Windows, MacOS e Unix/Linux.

Figura 1 - Pré-processamento dos dados

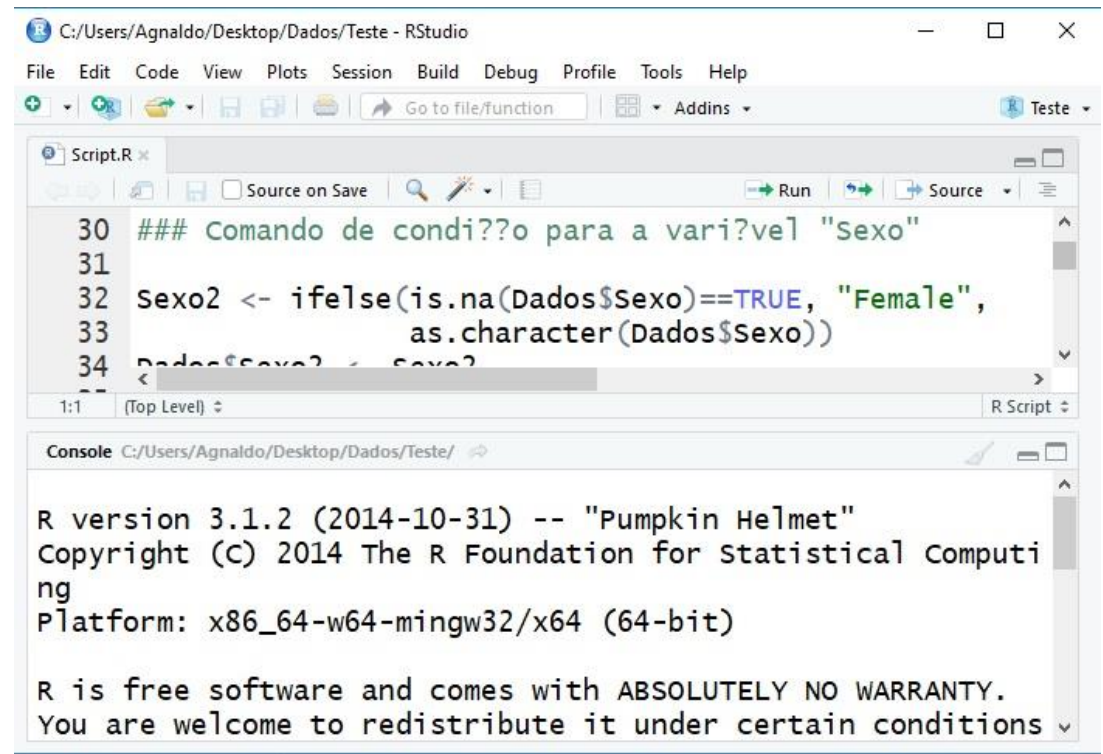

Fonte: Autoria própria.

Para a análise dos dados coletados da Plataforma Lattes, foram utilizadas as frequências absolutas e relativas para descrever as variáveis de interesse. Além disso, ponderaram-se os números absolutos pela quantidade de professores existentes em cada universidade. A fim de avaliar os fatores que exerciam influência na IES dos docentes, foi realizada inicialmente a análise univariada, via teste Qui-Quadrado (AGRESTI; KATERI, 2011).

\section{Resultados e discussões}

Para efeitos de comparação das patentes produzidas pelas duas IES, levou-se em conta a proporção dos docentes entre elas, sendo considerados, para a UTFPR, 2.598 pesquisadores e, para a UFABC, 661 pesquisadores. Para patentes que foram registradas por mais de um docente ou realizadas em conjunto, foi considerado apenas um registro.

Para quantificar e comparar as variáveis inovação, desenvolvimento e transferências definidas pela RUTyP, foram consideradas associadas a essas variáveis as patentes desenvolvidas e cadastradas no currículo Lattes dos pesquisadores das duas IES, divididas em três tipos:

a) patentes; 
b) softwares;

c) cartas, mapas e/ou similares.

Os resultados foram apresentados nas Tabelas 2, 3 e 4. Também foram comparadas, entre as IES, aquelas submetidas pelas agências de inovação (Tabelas 5, 6 e 7) e encontradas no banco de dados do INPI.

É importante salientar que nem todas as patentes encontradas no currículo Lattes foram submetidas às agências de inovação, pois há erros de preenchimento, dados incorretos, falta de atualização dos dados e até desinteresse do pesquisador em submeter a patente às agências de inovação.

\subsection{Patentes cadastradas na Plataforma Lattes}

\subsubsection{Patentes de invenção}

A Tabela 2 apresenta os resultados das patentes registradas no currículo Lattes dos docentes das duas IES, tendo como base o país, a área, o subtipo e o ano para cada universidade.

Tabela 2 - Patentes extraídas da Plataforma Lattes por variáveis de interesse para cada universidade

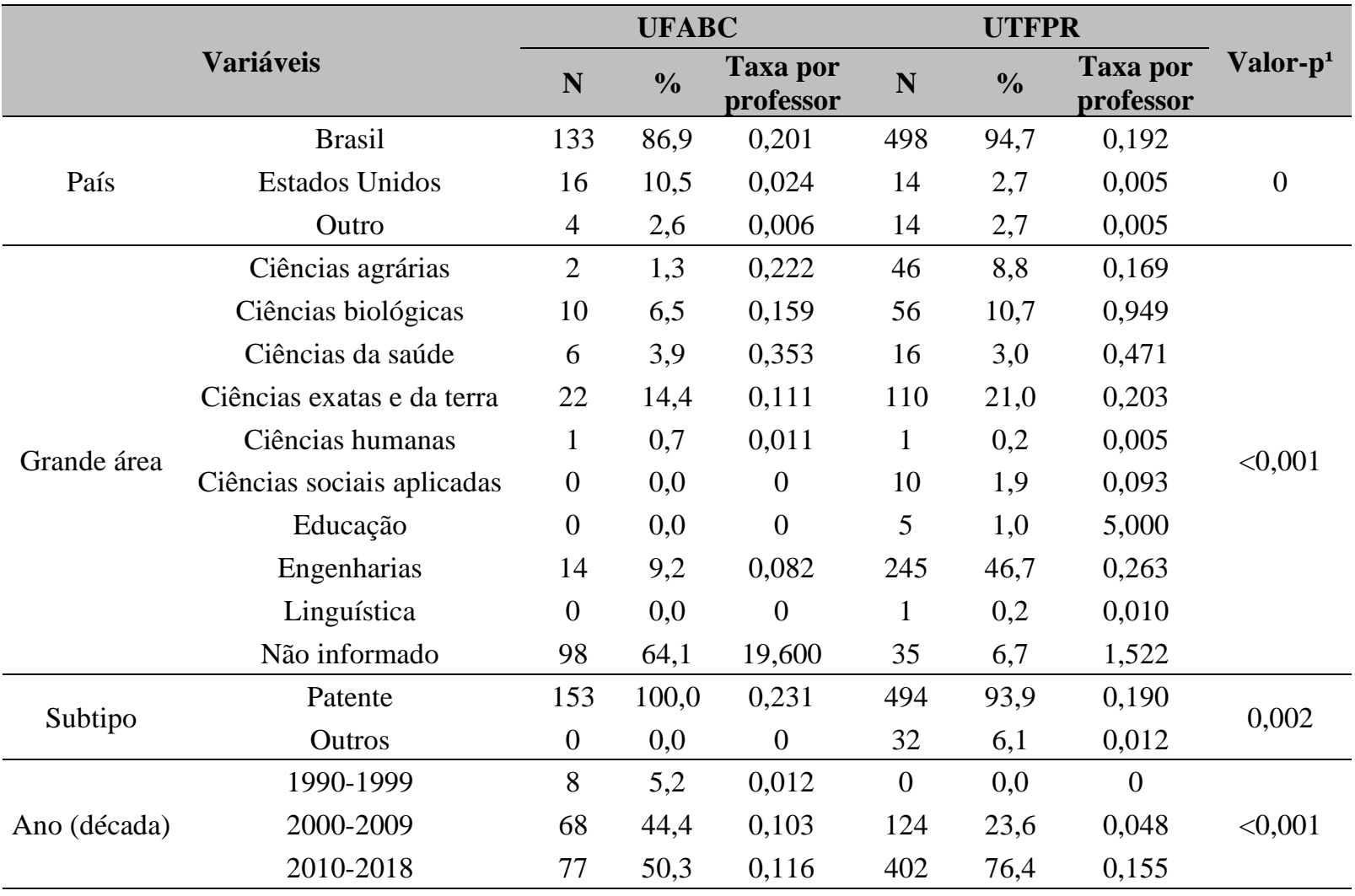

Fonte: Autoria própria.

Nota: ${ }^{1}$ Teste Qui-Quadrado Simulado. 
Dessa forma, tem-se que a UTFPR apresentou maior número de patentes por professor quando comparada com a UFABC.

Quando as patentes são filtradas pela grande área, a UTFPR tem maior número de patentes por professor em todas as áreas, comparada à UFABC. Destacam-se as áreas de ciências biológicas, ciências da saúde e engenharia da UTFPR, com maior percentual de patentes.

Quando selecionado o desempenho das IES por década, a UTFPR apresentou maior número de patentes por professor na década de 2010, enquanto a UFABC apresentou maior número de patentes por professor na década de 2000.

As patentes de inovação cadastradas pelos professores na Plataforma Lattes representam mera expectativa de serem documentadas e posteriormente homologadas, com a ajuda das agências de inovação, junto ao INPI. Apesar de não serem computadas pelo Ministério da Educação e Cultura (MEC) como patentes, podem retratar tipos de inovações desenvolvidas dentro das universidades.

A literatura aponta trabalhos que utilizaram a Plataforma Lattes para dimensionar produções intelectuais envolvendo patentes, como em Moura, Rozados e Caregnato (2006) e Oliveira e Velho (2009). Analisando somente os dados registrados pelos pesquisadores, tem-se a grande área de engenharia como a mais promissora para a tecnológica UTFPR, uma vez que essa instituição possui o maior número de patentes por inventor. Para a clássica UFABC, os destaques são as áreas de ciências exatas e da terra como as mais promissoras.

Se as análises dos dados fossem apoiadas apenas nos cadastros registrados na Plataforma Lattes, o modelo implementado pela tecnológica UTFPR teria destaque quando se trata de inovação, mas as patentes de inovação devem ser consideradas apenas quando sua concessão é realizada pelo INPI.

\subsubsection{Softwares}

No Brasil, qualquer programa de computador possui registro ou não tem sua propriedade intelectual protegida por lei, mesmo que não esteja legalizado pelo INPI. Por estar o programa de computador associado à automatização, à redundância de dados, ao ganho de performance, à agilidade, à segurança, à escalabilidade e à disponibilidade, dentre outras, suas aplicações são nas mais diversas áreas da indústria, do comércio e em serviços. Por esse motivo, é considerado um produto de inovação tecnológica e possui patente de inovação. 
Para facilitar os registros de softwares, o INPI disponibilizou um processo de concessão de patentes por meio da plataforma on-line, chamado e-RPC. Segundo dados estatísticos, nos últimos quatro anos, o número de registro de software tem dobrado a cada ano. As instituições de ensino e o governo são responsáveis por 37\% dos registros, $26 \%$ de empresas de médio e grande porte, $21 \%$ de pessoas físicas, $11 \%$ de empresas de pequeno porte, $5 \%$ associações (INSTITUTO NACIONAL DE PROPRIEDADE INTELECTUAL, 2018).

Para normatizar o registro de software no Brasil, o desenvolvimento de programas de computador está amparado pela Lei $n^{0} 9.609 / 98$ e na Lei $n^{\circ} 9.610 / 98$, que conferem proteção por propriedade intelectual. Eles podem ser registrados para garantir a seu inventor maior segurança jurídica, caso haja demanda judicial para comprovar autoria ou titularidade.

A Tabela 3 apresenta a quantidade de softwares por país, área, subtipo e ano para cada universidade. Quando comparada a quantidade de software, a UTFPR apresentou maior número de softwares por subtipos e décadas por professor, em todas as áreas.

Tabela 3 - Softwares extraídos da Plataforma Lattes por variáveis de interesse para cada universidade

\begin{tabular}{|c|c|c|c|c|c|c|c|c|}
\hline & \multirow[b]{2}{*}{ Variáveis } & \multicolumn{3}{|c|}{ UFABC } & \multicolumn{3}{|c|}{ UTFPR } & \multirow[b]{2}{*}{ Valor-p } \\
\hline & & $\mathbf{N}$ & $\%$ & $\begin{array}{l}\text { Taxa por } \\
\text { professor }\end{array}$ & $\mathbf{N}$ & $\%$ & $\begin{array}{l}\text { Taxa por } \\
\text { professor }\end{array}$ & \\
\hline \multirow{2}{*}{ País } & Brasil & 184 & 94,4 & 0,278 & 1441 & 98,4 & 0,555 & \multirow{2}{*}{0,001} \\
\hline & Outro & 11 & 5,6 & 0,017 & 23 & 1,6 & 0,009 & \\
\hline \multirow{9}{*}{ Grande área } & Ciências agrárias & 0 & 0,0 & 0,000 & 39 & 2,7 & 0,143 & \multirow{9}{*}{$<0,001$} \\
\hline & Ciências biológicas & 0 & 0,0 & 0,000 & 24 & 1,6 & 0,407 & \\
\hline & Ciências da saúde & 2 & 1,0 & 0,118 & 18 & 1,2 & 0,529 & \\
\hline & Ciências exatas e da terra & 14 & 7,2 & 0,071 & 373 & 25,5 & 0,687 & \\
\hline & Ciências humanas & 0 & 0,0 & 0,000 & 48 & 3,3 & 0,255 & \\
\hline & Ciências sociais aplicadas & 1 & 0,5 & 0,022 & 38 & 2,6 & 0,352 & \\
\hline & Educação & 1 & 0,5 & 1,000 & 53 & 3,6 & 53,000 & \\
\hline & Engenharias & 16 & 8,2 & 0,094 & 228 & 15,6 & 0,245 & \\
\hline & Não informado & 161 & 82,6 & 32,200 & 643 & 43,9 & 27,957 & \\
\hline \multirow{4}{*}{ Subtipo } & Computacional & 75 & 38,5 & 0,113 & 697 & 47,6 & 0,268 & \multirow{4}{*}{0,002} \\
\hline & Multimídia & 4 & 2,1 & 0,006 & 114 & 7,8 & 0,044 & \\
\hline & Não informado & 116 & 59,5 & 0,175 & 650 & 44,4 & 0,250 & \\
\hline & Outro & 0 & 0,0 & 0,000 & 3 & 0,2 & 0,001 & \\
\hline \multirow{5}{*}{ Ano (década) } & 1980-1989 & 0 & 0,0 & 0,000 & 9 & 0,6 & 0,003 & \multirow{5}{*}{$<0,001$} \\
\hline & 1990-1999 & 0 & 0,0 & 0,000 & 183 & 12,5 & 0,070 & \\
\hline & 2000-2009 & 91 & 46,7 & 0,138 & 691 & 47,2 & 0,266 & \\
\hline & 2010-2018 & 104 & 53,3 & 0,157 & 580 & 39,6 & 0,223 & \\
\hline & Não informado & 0 & 0,0 & 0,000 & 1 & 0,1 & 0,000 & \\
\hline
\end{tabular}

Fonte: Autoria própria.

Nota: ${ }^{1}$ Teste Qui-Quadrado Simulado. 
As áreas da tecnológica UTFPR que possuem maior quantidade de software registrados na Plataforma Lattes são principalmente a área de ciências extadas e da terra, com $25,5 \%$ de todos os softwares registrados, e a área de engenharia, com 15,6\%. Para a clássica UFABC, a área de invento de $82,6 \%$ de seus softwares não foi informada. Nos relatórios fornecidos pelo Instituto Nacional de Propriedade Intelectual (2018), o tipo de pedido com maior quantidade de concessões tem a ver com os programas de computadores.

\subsubsection{Cartas, mapas ou similares}

O INPI permite o patenteamento e a exclusividade sobre um nome, produto, logotipo ou ainda um desenho industrial. O registro garante a seu titular o direito de uso exclusivo em todo território nacional por dez anos e renovação por mais dez anos, a partir da sua concessão (INSTITUTO NACIONAL DE PROPRIEDADE INTELECTUAL, 2018). O registro de marcas, modelos de utilidades, desenho industrial estão entre os maiores pedidos realizados para concessão de patentes, depois de patentes de inovação e programas de computadores.

Como mostra a Tabela 4, a UTFPR apresentou maior número de cartas, mapas ou similares por professor nas áreas de ciências exatas e da terra e ciências sociais aplicadas, enquanto a UFABC apresentou maior número de cartas, mapas ou similares nas outras áreas.

Tabela 4 - Cartas, mapas ou similares extraídos da Plataforma Lattes por variáveis de interesse para cada universidade

\begin{tabular}{|c|c|c|c|c|c|c|c|c|}
\hline \multirow{2}{*}{\multicolumn{2}{|c|}{ Variáveis }} & \multicolumn{3}{|c|}{ UFABC } & \multicolumn{3}{|c|}{ UTFPR } & \multirow[b]{2}{*}{ Valor-p ${ }^{1}$} \\
\hline & & $\mathbf{N}$ & $\%$ & $\begin{array}{l}\text { Taxa por } \\
\text { professor }\end{array}$ & $\mathbf{N}$ & $\%$ & $\begin{array}{l}\text { Taxa por } \\
\text { professor }\end{array}$ & \\
\hline \multirow{2}{*}{ País } & Brasil & 8 & 100,0 & 0,012 & 22 & 95,7 & 0,008 & \multirow{2}{*}{1,000} \\
\hline & Espanha & 0 & 0,0 & 0,000 & 1 & 4,3 & 0,000 & \\
\hline \multirow{6}{*}{ Grande área } & Ciências agrárias & 1 & 12,5 & 0,111 & 3 & 13,0 & 0,011 & \multirow{6}{*}{0,035} \\
\hline & Ciências biológicas & 3 & 37,5 & 0,048 & 0 & 0,0 & 0,000 & \\
\hline & Ciências exatas e da terra & 1 & 12,5 & 0,005 & 11 & 47,8 & 0,020 & \\
\hline & Ciências sociais aplicadas & 2 & 25,0 & 0,043 & 6 & 26,1 & 0,056 & \\
\hline & Engenharias & 1 & 12,5 & 0,006 & 1 & 4,3 & 0,001 & \\
\hline & Não informado & 0 & 0,0 & 0,000 & 2 & 8,7 & 0,087 & \\
\hline \multirow{4}{*}{ Subtipo } & Aerofotograma & 0 & 0,0 & 0,000 & 2 & 8,7 & 0,001 & \multirow{4}{*}{0,476} \\
\hline & Carta & 1 & 12,5 & 0,002 & 5 & 21,7 & 0,002 & \\
\hline & Mapa & 7 & 87,5 & 0,011 & 14 & 60,9 & 0,005 & \\
\hline & Outro & 0 & 0,0 & 0,000 & 2 & 8,7 & 0,001 & \\
\hline \multirow{3}{*}{ Ano (década) } & 1990-1999 & 1 & 12,5 & 0,002 & 2 & 8,7 & 0,001 & \multirow{3}{*}{1,000} \\
\hline & 2000-2009 & 5 & 62,5 & 0,008 & 17 & 73,9 & 0,007 & \\
\hline & $2010-2018$ & 2 & 25,0 & 0,003 & 4 & 17,4 & 0,002 & \\
\hline
\end{tabular}

Fonte: Autoria própria.

Nota: ${ }^{1}$ Teste Qui-Quadrado Simulado. 
A UTFPR apresentou maior número de cartas, mapas ou similares por professor em todos os subtipos, quando comparada com a UFABC, exceto mapa e carta. A UFABC apresentou maior número de cartas, mapas ou similares por professor em todas as décadas.

\subsection{Patentes cadastradas no INPI}

\subsubsection{Patentes de invenção}

Quando uma patente de invenção é submetida ao processo de patenteamento do INPI, ela pode adquirir os seguintes status do órgão: concedida, indeferida e indeferida/recurso. Antes de ser concedida, existe a busca de anterioridade para constatar similaridades ou a existência da patente, assim, pode ser indeferida quando há similaridade. Quando a patente não for concedida, um recurso pode ser submetido, com as justificativas técnicas.

Quanto às patentes submetidas ao INPI pela UTFPR, há 178 patentes de invenção, sendo 13 concedidas, 158 em processo, 4 indeferidas e 3 patentes com recursos.

Em relação aos tipos de patente, pode-se classificá-las em:

a) patente de invenção: relacionada a algo inédito, que não existe no mercado, e sua concessão está associada à relevância tecnológica;

b) patente modelo de utilidade: caracteriza produto ou processo existente, mas com melhoria, como uma nova forma de uso;

c) patente de topografia de circuitos integrados: é caracterizada pela construção de um chip eletrônico.

No que tange aos tipos de patentes, para a UTFPR há: 140 patentes de invenção, 18 patentes modelo de utilidade e 2 patentes de topografia de circuitos integrados.

Já a clássica UFABC submeteu ao INPI 51 patentes, estando 45 em processo, 3 arquivadas, 2 indeferidas, 1 em recurso e nenhuma concedida.

Analisando os dados das patentes homologadas (Tabela 5), houve associação significativa entre a grande área e as universidades, quanto à quantidade de patentes, e a UFABC obteve maior percentual de patentes submetidas na área de ciências exatas e da terra, enquanto a UTFPR obteve maior percentual de patentes submetidas na área de engenharia. 
Tabela 5 - Análise descritiva de patentes encontradas nos bancos de dados das agências de inovação e do INPI

\begin{tabular}{|c|c|c|c|c|c|}
\hline \multirow{3}{*}{ Variáveis } & \multicolumn{5}{|c|}{ Patentes } \\
\hline & \multicolumn{2}{|c|}{ UFABC } & \multicolumn{2}{|c|}{ UTFPR } & \multirow{2}{*}{$\begin{array}{c}\text { Valor } \\
(-p)\end{array}$} \\
\hline & $\mathbf{N}$ & $\%$ & $\mathbf{N}$ & $\%$ & \\
\hline \multicolumn{6}{|l|}{ Ano } \\
\hline 2002 & 0 & 0 & 1 & 0,6 & \multirow{15}{*}{$0,084^{2}$} \\
\hline 2004 & 0 & 0 & 2 & 1,1 & \\
\hline 2006 & 1 & 2 & 2 & 1,1 & \\
\hline 2007 & 0 & 0 & 1 & 0,6 & \\
\hline 2008 & 0 & 0 & 1 & 0,6 & \\
\hline 2009 & 0 & 0 & 3 & 1,7 & \\
\hline 2010 & 0 & 0 & 8 & 4,5 & \\
\hline 2011 & 2 & 3,9 & 4 & 2,3 & \\
\hline 2012 & 5 & 9,8 & 12 & 6,7 & \\
\hline 2013 & 9 & 18,0 & 20 & 11,2 & \\
\hline 2014 & 10 & 20,0 & 12 & 6,7 & \\
\hline 2015 & 6 & 12,0 & 21 & 11,8 & \\
\hline 2016 & 11 & 22,0 & 26 & 14,6 & \\
\hline 2017 & 4 & 7,8 & 38 & 21,4 & \\
\hline 2018 & 3 & 5,9 & 27 & 15,2 & \\
\hline \multicolumn{6}{|l|}{ Processo } \\
\hline Arquivado & 0 & 0 & 0 & 0,0 & \multirow{5}{*}{$0,917^{1}$} \\
\hline Concedido & 3 & 5,9 & 13 & 7,3 & \\
\hline Em processo & 47 & 92,0 & 158 & 89 & \\
\hline Indeferida & 0 & 0 & 4 & 2,3 & \\
\hline Indeferida/Recurso & 1 & 2 & 3 & 1,7 & \\
\hline \multicolumn{6}{|l|}{ Grande área } \\
\hline Ciências agrárias & 1 & 2,0 & 17 & 9,6 & \multirow{7}{*}{$<0,001^{1}$} \\
\hline Ciências biológicas & 4 & 7,8 & 5 & 2,8 & \\
\hline Ciências da saúde & 4 & 7,8 & 12 & 6,8 & \\
\hline Ciências exatas e da terra & 23 & 45,0 & 27 & 15,0 & \\
\hline Ciências humanas & 2 & 3,9 & 1 & 0,6 & \\
\hline Ciências sociais aplicadas & 0 & 0,0 & 2 & 1,1 & \\
\hline Engenharias & 17 & 33 & 113 & 64 & \\
\hline
\end{tabular}

Fonte: Autoria própria.

Nota: ${ }^{1}$ Teste Exato de Fisher; ${ }^{2}$ Teste Qui-Quadrado Simulado.

Devido à diferença de pesquisadores entre as IES, a relação (quantidade de pesquisadores/quantidade de patentes) em termos proporcionais, não se pode afirmar que a UTFPR possui quantidade significativa de patentes em relação à UFABC.

\subsubsection{Software}

Quando se analisam as patentes de softwares (Tabela 6) submetidas ao INPI, há 67 patentes de softwares registradas para a UFABC e 128 para a UTFPR. Nessa análise, foi 
encontrada associação significativa entre o ano e as universidades quanto à quantidade de softwares registrados, e a UFABC possui maior percentual de softwares homologados no ano de 2017, enquanto a UTFPR possui maior percentual de softwares registrados em 2018.

Tabela 6 - Análise descritiva de softwares encontrados nos bancos de dados das agências de inovação e do INPI

\begin{tabular}{|c|c|c|c|c|c|}
\hline \multirow{3}{*}{ Variáveis } & \multicolumn{5}{|c|}{ Softwares } \\
\hline & \multicolumn{2}{|c|}{ UFABC } & \multicolumn{2}{|c|}{ UTFPR } & \multirow{2}{*}{$\begin{array}{c}\text { Valor } \\
(-p)\end{array}$} \\
\hline & $\mathbf{N}$ & $\%$ & $\mathbf{N}$ & $\%$ & \\
\hline \multicolumn{6}{|l|}{ Ano } \\
\hline 2002 & 0 & 0,0 & 0 & 0,0 & \multirow{15}{*}{$<0,001^{2}$} \\
\hline 2004 & 0 & 0,0 & 0 & 0,0 & \\
\hline 2006 & 0 & 0,0 & 0 & 0,0 & \\
\hline 2007 & 0 & 0,0 & 2 & 1,6 & \\
\hline 2008 & 0 & 0,0 & 0 & 0,0 & \\
\hline 2009 & 0 & 0,0 & 0 & 0,0 & \\
\hline 2010 & 0 & 0,0 & 2 & 1,6 & \\
\hline 2011 & 3 & 4,5 & 0 & 0,0 & \\
\hline 2012 & 0 & 0,0 & 1 & 0,8 & \\
\hline 2013 & 4 & 6,0 & 1 & 0,8 & \\
\hline 2014 & 5 & 7,5 & 6 & 4,7 & \\
\hline 2015 & 12 & 17,9 & 2 & 1,6 & \\
\hline 2016 & 6 & 9,0 & 4 & 3,1 & \\
\hline 2017 & 34 & 50,8 & 40 & 31,3 & \\
\hline 2018 & 3 & 4,5 & 70 & 54,7 & \\
\hline \multicolumn{6}{|l|}{ Processo } \\
\hline Arquivado & 0 & 0,0 & 0 & 0,0 & \multirow{5}{*}{$0,053^{1}$} \\
\hline Concedido & 67 & 100 & 120 & 93,8 & \\
\hline Em processo & 0 & 0,0 & 8 & 6,3 & \\
\hline Indeferida & 0 & 0,0 & 0 & 0,0 & \\
\hline Indeferida/Recurso & 0 & 0,0 & 0 & 0,0 & \\
\hline \multicolumn{6}{|l|}{ Grande área } \\
\hline Ciências agrárias & 1 & 1,5 & 6 & 4,7 & \multirow{7}{*}{$<0,001^{2}$} \\
\hline Ciências biológicas & 0 & 0,0 & 3 & 2,3 & \\
\hline Ciências da saúde & 0 & 0,0 & 9 & 7,0 & \\
\hline Ciências exatas e da terra & 26 & 38,8 & 56 & 44,0 & \\
\hline Ciências humanas & 37 & 55,2 & 23 & 18,0 & \\
\hline Ciências sociais aplicadas & 1 & 1,5 & 24 & 19,0 & \\
\hline Engenharias & 2 & 3,0 & 7 & 5,5 & \\
\hline
\end{tabular}

Fonte: Autoria própria.

Nota: ${ }^{1}$ Teste Exato de Fisher; ${ }^{2}$ Teste Qui-Quadrado Simulado. 
Destaca-se a grande área das universidades quanto à quantidade de softwares registrados, e a UFABC obteve maior percentual de softwares submetidos na área de ciências humanas, enquanto a UTFPR obteve maior percentual de softwares submetidos na área de ciências exatas e da terra.

Houve diferença significativa entre as universidades com relação às proporções de softwares homologados, e a UFABC obteve maior proporção de softwares homologados por professor.

\subsubsection{Patentes de cartas, mapas ou similares}

A Tabela 7 mostra 21 registros de cartas, mapas ou similares, sendo 10 em processo, 8 concedidos, 1 indeferido, 1 arquivado e 1 em recurso, divididos em 20 marcas e 1 desenho industrial. Não foram encontrados registros desse modelo de patente para a clássica UFABC, portanto, houve diferença significativa entre as universidades com relação às proporções de cartas, mapas ou similares homologados, e a UTFPR obteve maior proporção de cartas, mapas ou similares homologados. 
Tabela 7 - Análise descritiva de cartas encontradas nos bancos de dados das agências de inovação e do INPI

\begin{tabular}{|c|c|c|c|c|c|}
\hline \multirow{3}{*}{ Variáveis } & \multicolumn{5}{|c|}{ Softwares } \\
\hline & \multicolumn{2}{|c|}{ UFABC } & \multicolumn{2}{|c|}{ UTFPR } & \multirow{2}{*}{$\begin{array}{c}\text { Valor } \\
(-p)\end{array}$} \\
\hline & $\mathbf{N}$ & $\%$ & $\mathbf{N}$ & $\%$ & \\
\hline \multicolumn{6}{|l|}{ Ano } \\
\hline 2002 & - & - & 0 & 0,0 & \\
\hline 2004 & - & - & 0 & 0,0 & \\
\hline 2006 & - & - & 0 & 0,0 & \\
\hline 2007 & - & - & 2 & 9,5 & \\
\hline 2008 & - & - & 1 & 4,8 & \\
\hline 2009 & - & - & 0 & 0,0 & \\
\hline 2010 & - & - & 2 & 9,5 & \\
\hline 2011 & - & - & 0 & 0,0 & - \\
\hline 2012 & - & - & 0 & 0,0 & \\
\hline 2013 & - & - & 1 & 4,8 & \\
\hline 2014 & - & - & 0 & 0,0 & \\
\hline 2015 & - & - & 3 & 14,3 & \\
\hline 2016 & - & - & 1 & 4,8 & \\
\hline 2017 & - & - & 11 & 52,4 & \\
\hline 2018 & - & - & 0 & 0,0 & \\
\hline \multicolumn{6}{|l|}{ Processo } \\
\hline Arquivado & - & - & 1 & 4,8 & \\
\hline Concedido & - & - & 8 & 38,1 & \\
\hline Em processo & - & - & 10 & 47,6 & - \\
\hline Indeferida & - & - & 1 & 4,8 & \\
\hline Indeferida/Recurso & - & - & 1 & 4,8 & \\
\hline \multicolumn{6}{|l|}{ Grande área } \\
\hline Ciências agrárias & - & - & 0,0 & 0,0 & \\
\hline Ciências biológicas & - & - & 0,0 & 0,0 & \\
\hline Ciências da saúde & - & - & 0,0 & 0,0 & \\
\hline Ciências exatas e da terra & - & - & 0,0 & 0,0 & - \\
\hline Ciências humanas & - & - & 0,0 & 0,0 & \\
\hline Ciências sociais aplicadas & - & - & 21,0 & 100,0 & \\
\hline Engenharias & - & - & 0,0 & 0,0 & \\
\hline
\end{tabular}

Fonte: Autoria própria.

Nota: ${ }^{1}$ Teste Exato de Fisher; ${ }^{2}$ Teste Qui-Quadrado Simulado.

\subsection{Classificação das patentes de invenção}

\subsubsection{Patentes concedidas}

Desde o depósito no INPI, o pedido de patente passa por várias etapas: exame formal, publicação, pedido de exame e o exame substantivo. O resultado do exame substantivo pode ser no sentido da concessão da patente ou de seu indeferimento. A tramitação do processo até essa decisão técnica tem levado, em média, 11 anos, causando grande atraso na inovação, 
reduzindo o estímulo e as ofertas de novos produtos e serviços para a sociedade (SILVA; BORSCHIVER, 2009). O grande desafio do sistema nacional de patentes é a redução do chamado tempo backlog, termo técnico utilizado para indicar o acúmulo de pedidos à espera de decisão do Instituto Nacional de Propriedade Intelectual (2018).

As patentes de inovação concedidas representam importantes documentos e fontes de informação para verificação dos indicadores científicos e tecnológicos (BICALHO; FERREIRA, 2010). Para classificação das patentes por assunto, segue-se a classificação internacional, do inglês, International Patent Classification (IPC), que estabelece normas de classificação hierárquica de acordo com os campos tecnológicos, utilizando uma tabela desenvolvida com a metodologia OMPI, que relaciona os símbolos IPC aos campos tecnológicos correspondentes (SCARTASSINI, 2015).

As principais áreas estabelecidas pelo IPC são compostas por:

a) necessidades humanas;

b) operações de processamento, transporte;

c) química, metalurgia;

d) têxteis, papel;

e) construções fixas;

f) engenharia mecânica, iluminação, aquecimento, armas, explosão;

g) física;

h) eletricidade, com vários níveis de subáreas.

A Figura 2 traz um exemplo de classificação das patentes pelo IPC, disponibilizado no relatório anual do INPI de 2018. As áreas com maior submissão de patentes no ano de 2015 foram: química orgânica fina, tecnologia médica e produtos farmacêuticos, representando $28 \%$ das patentes tecnológicas mais pedidas (INSTITUTO NACIONAL DE PROPRIEDADE INTELECTUAL, 2018). 
Figura 2 - Pedidos de Patente de Invenção de 2015, classificados pelo IPC

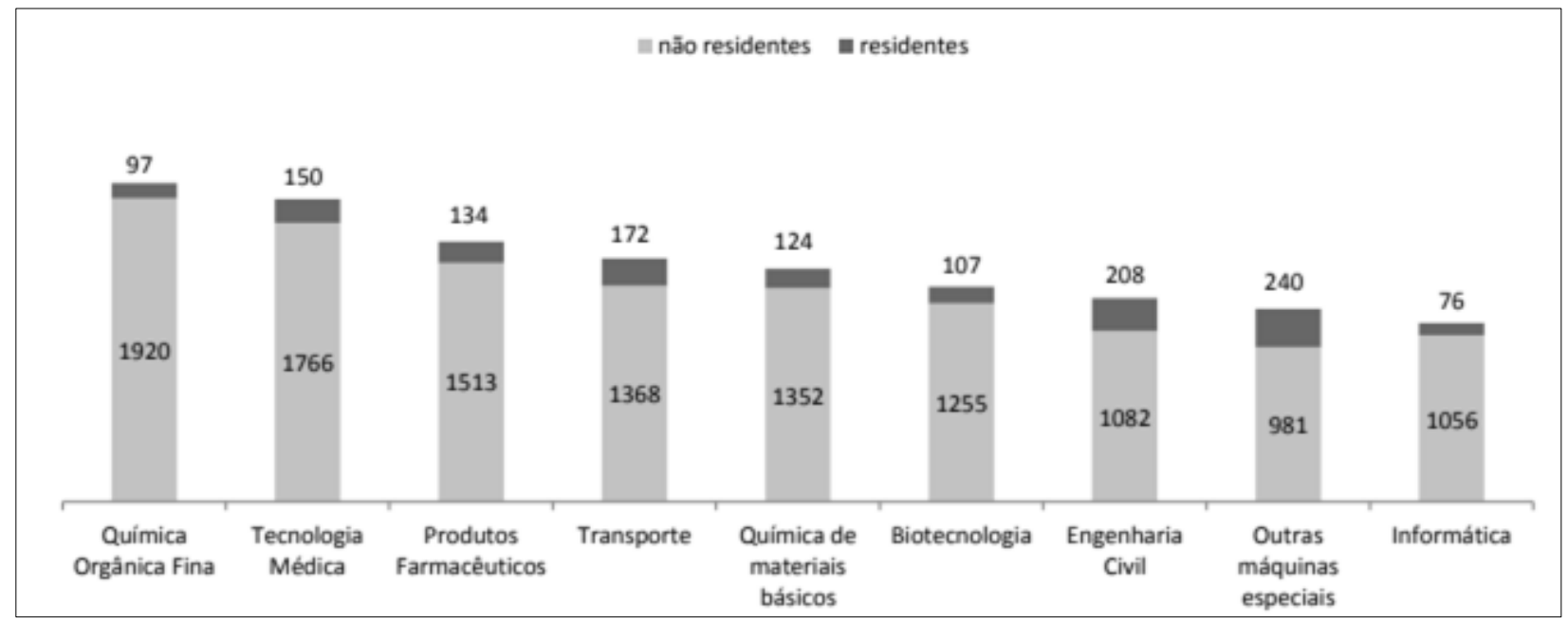

Fonte: Instituto Nacional de Propriedade Intelectual (2018).

Nas 13 patentes classificadas pelo IPC e concedidas para a UTFPR, são destaques as áreas de: necessidades humanas, com sete inventos nas áreas de agricultura e uma em produtos alimentícios, seguida das áreas de física, com quatro instrumentos de medição, e operação de processamento, com uma patente de separação e mistura (Figura 2). Ao analisar o perfil das patentes de invenção concedidas, a UTFPR, até o momento, tem $60 \%$ das patentes relacionadas aos instrumentos aplicados nas áreas agrícola, alimentícia e física.

Para a área de necessidades humanas da tecnológica UTFPR, os inventos são originários das cidades de Dois Vizinhos e de Francisco Beltrão, que se localizam no interior do estado. Outro destaque na classificação do IPC são as áreas de física, na solução de produtos de medição, com quatro patentes concedidas.

\subsubsection{Patentes à espera de concessão}

Para patentes que aguardam a concessão do INPI, foram classificadas 51 da clássica UFABC e 158 da tecnológica UTFPR (Figura 3). 
Figura 3 - Classificação Internacional das Patentes (IPC) em processo de concessão da UFABC e UTFPR

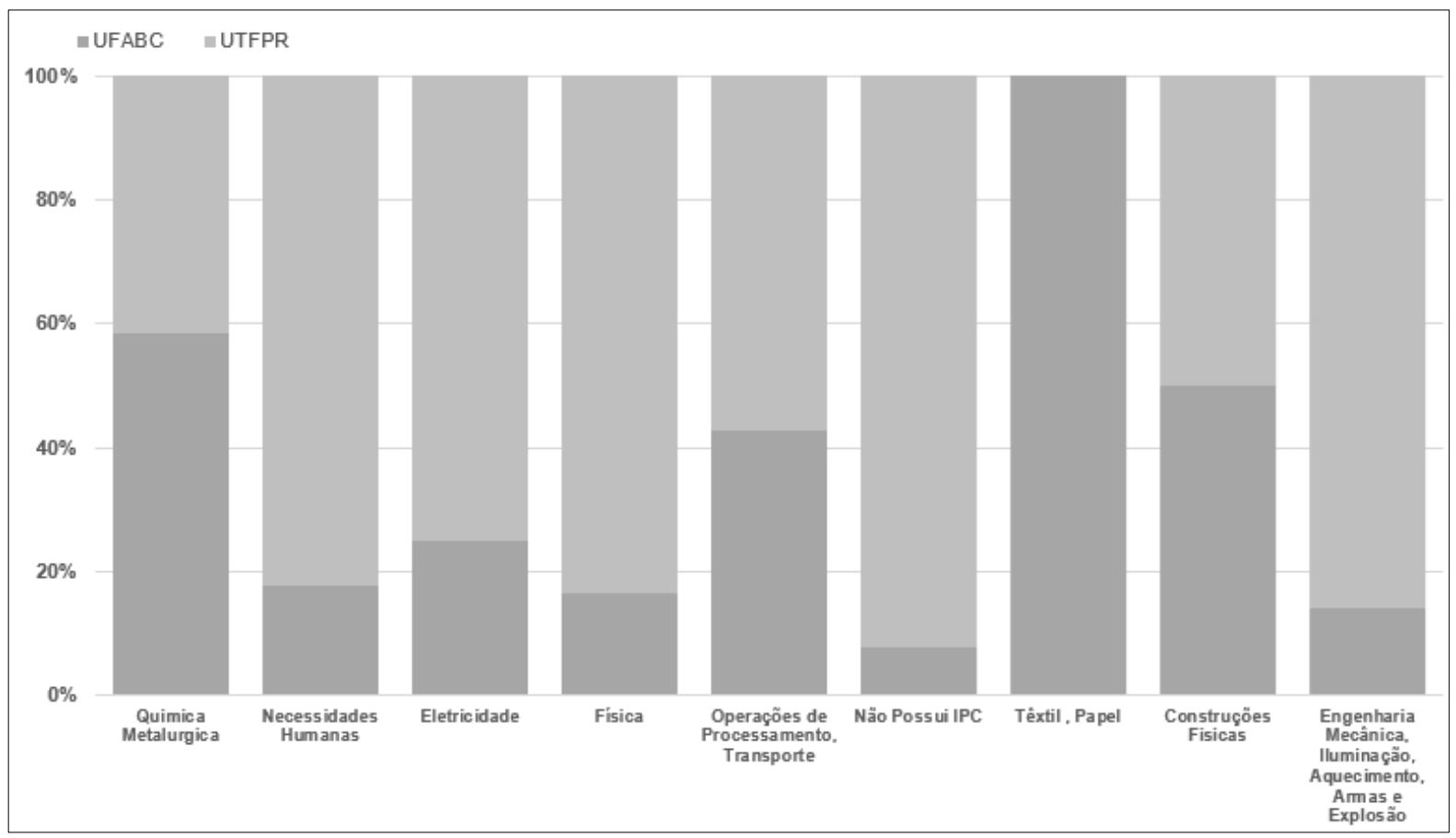

Considerando as tendências das patentes de inovação submetidas ao INPI, a UFABC está mais próxima da área de química metalúrgica em patentes de invenção. A instituição é responsável pela grande maioria dos depósitos entre os anos de 2015 e 2018, no Brasil, na área (Figura 3).

Para a tecnológica UTFPR, são destaques a área de necessidades humanas (agricultura, produtos alimentícios, artigos pessoais, ciências médicas etc.) e a área de física (medição, teste, tecnologia da informação, armazenamento de dados, física nuclear, ótica etc.). As patentes da UTFPR que aguardam os processos de concessão seguem a tendência das patentes já concedidas (Figura 4). 


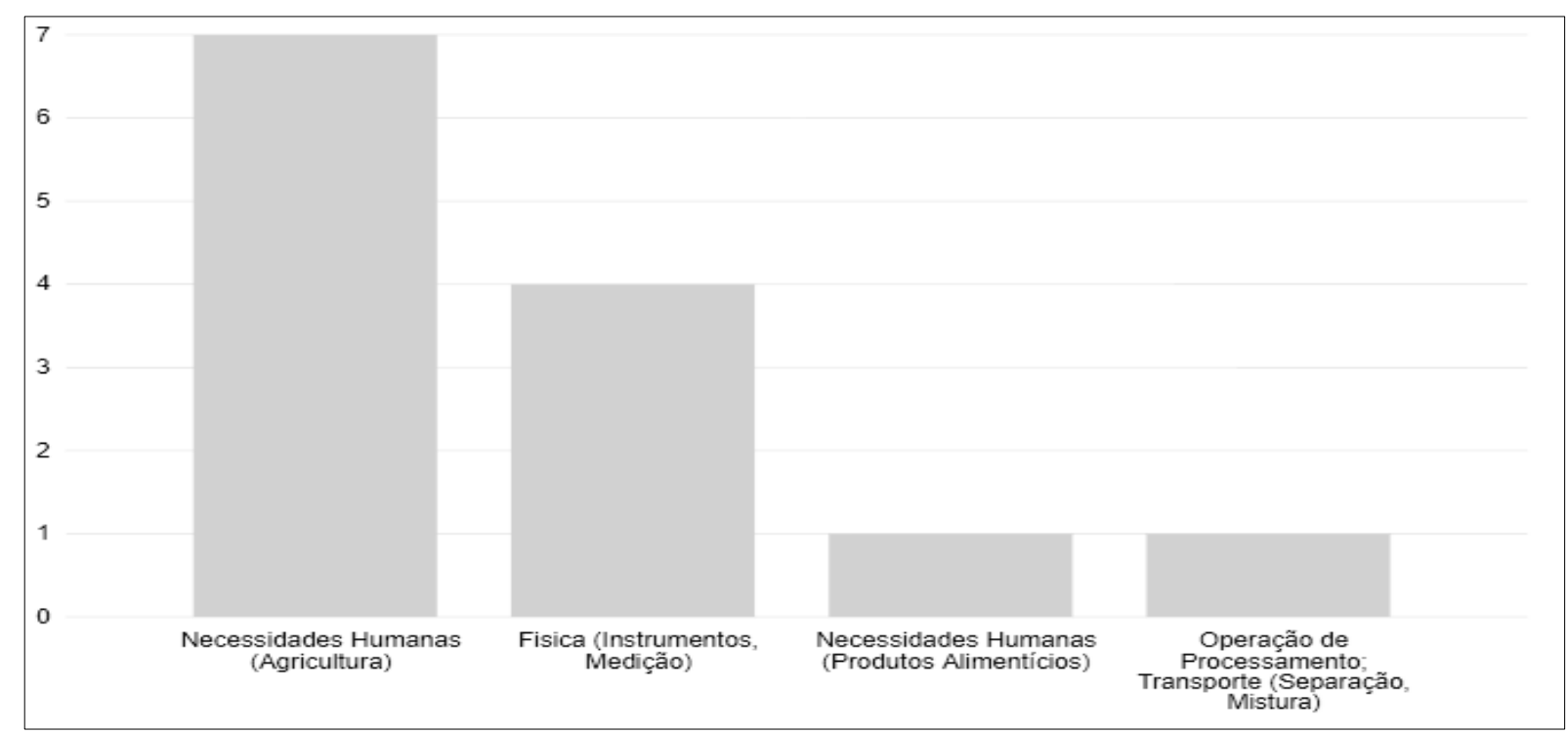

Fonte: Autoria própria.

Dessa forma, emergem as áreas mais promissoras para concessão de patentes nos próximos anos das duas IES. Para a clássica UFABC, tem-se a área de química e metalurgia (química orgânica e inorgânica, fertilizantes, corantes, tratamento de águas, bioquímica, materiais metálicos, revestimento de materiais, ligas metálicas, principalmente), com aplicações nas indústrias de petroquímicos, agroquímicos, produtos farmacêuticos. Para a tecnológica UTFPR, as melhores possibilidades estão na agricultura.

A UTFPR, na classificação geral de 2015 no RUF, no quesito inovação, ocupava a $31^{\text {a }}$ posição geral. No ano de 2018 , essa posição saltou para a $22^{a}$ colocação. Isso não aconteceu com a UFABC, que estava na $31^{\text {a }}$ posição em 2015 , mas em 2018 passou a ocupar a $71^{\text {a }}$ posição (RANKING..., 2018).

\subsection{Patentes cadastradas na Plataforma Lattes $x$ patentes cadastradas no INPI}

Para confrontar a quantidade de patentes que foram extraídas da Plataforma Lattes com as patentes submetidas ao INPI (Tabela 8), foram realizadas comparações para medir a efetividade das ações das agências de inovação. 
Tabela 8 - Os dados apresentados representam as proporções de patentes, softwares e cartas homologados pela UTFPR e UFABC em relação as encontradas na Plataforma lattes

\begin{tabular}{cccccccc}
\hline \multirow{2}{*}{ Fonte } & \multicolumn{9}{c}{ UFABC } & \multicolumn{5}{c}{ UTFPR } \\
& $\begin{array}{c}\text { Total } \\
\text { Lattes }\end{array}$ & $\begin{array}{c}\text { Não } \\
\text { homologadas }\end{array}$ & $\begin{array}{c}\text { \% } \\
\text { homologadas }\end{array}$ & $\begin{array}{c}\text { Total } \\
\text { Lattes }\end{array}$ & $\begin{array}{c}\text { Não } \\
\text { homologadas }\end{array}$ & $\begin{array}{c}\text { \% } \\
\text { homologadas }\end{array}$ & Valor-p \\
\hline Patentes & 153 & 51 & $33,3 \%$ & 526 & 178 & $33,8 \%$ & 0,984 \\
Softwares & 195 & 67 & $34,4 \%$ & 1.464 & 128 & $8,7 \%$ & $<0,001$ \\
$\begin{array}{c}\text { Cartas, mapas e } \\
\text { similares }\end{array}$ & 8 & 0 & $0,0 \%$ & 23 & 21 & $91,3 \%$ & $<0,001$ \\
\hline
\end{tabular}

Fonte: Autoria própria.

Nota: ${ }^{1}$ Teste Exato de Fisher; ${ }^{2}$ Teste Qui-Quadrado Simulado.

Quanto às patentes de invenção, 33\% das patentes da UTFPR e da UFABC foram submetidas ao INPI, ficando um percentual de $67 \%$ de patentes que podem ser submetidas.

Quanto às patentes de software encontradas no currículo Lattes dos pesquisadores da UFABC, 34,4\% foram convertidas em patentes de software. A UTFPR possui grande potencial de aumentar significativamente as patentes de software, pois se constatou que apenas $8,7 \%$ dos dados cadastrados na Plataforma Lattes foram homologados no INPI.

As patentes de cartas, mapas ou similares encontradas no currículo Lattes dos pesquisadores da UTFPR apresentam 91,3\% de homologação. A clássica UFABC não apresenta patente homologada para cartas, mapas ou similares.

Sobre as patentes cadastradas no currículo Lattes, e não submetidas às agências de inovação para concessão de titularidade, cabe à universidade a execução de medidas e de sensibilização sobre a importância de obter as patentes para o meio acadêmico e para o país (SANTOS; ROSSI, 2002).

\subsection{Transferência de tecnologia}

A transferência de tecnologia das universidades para empresas do setor produtivo no Brasil caminha a passos lentos. Os dados apontam assimetria entre o número de patentes concedidas às universidades e os contratos de licenciamento celebrados pelas instituições de ensino com os setores industriais. O tema é recente na literatura, mas se encontram diversos estudos que enfatizam essa temática, como Closs e Ferreira (2012), que realizaram estudos sobre artigos científicos envolvendo transferência entre empresas e universidades entre os anos de 2005 e 2009.

Cysne (2005) explora e aborda a transferência de tecnologia entre a universidade e a indústria. Closs et al. (2012) realizam um estudo de transferência de tecnologia em um estudo de caso da PUCRS. Berni et al. (2015) estudam a interação universidade-empresa para a inovação e a transferência de tecnologia. Nesses estudos, os autores têm como objetivo 
descrever as dificuldades e os caminhos que podem ser perseguidos para que a integração entre universidades e empresas seja realizada de forma mais efetiva.

Essa discrepância pode estar relacionada a dois fatores: o tipo de produto de inovações que as universidades estão produzindo, sem ouvir o que o setor industrial precisa; ou a ineficiência dos mecanismos para aprimorar a relação das universidades com as empresas, a fim de produzir inovações que possam ser utilizadas pelo setor industrial. Essa união, segundo Barbosa (2006), é ponto nodal para o processo de inovação.

Nos relatórios do Formict, produzidos pelo Ministério da Ciência, Tecnologia e Inovação, constata-se que apenas 58 instituições informaram possuir contratos de transferência de tecnologia, sendo 42 instituições públicas e 16 privadas. Em relação às instituições que não possuem contratos de transferência de tecnologia firmados em 2016, 151 são instituições públicas e 69 são instituições privadas, totalizando 220 instituições (BRASIL, 2017).

Do banco de dados do INPI foram extraídas informações das IES em estudo sobre patentes de inovação que foram transferidas para os setores produtivos, com o objetivo de analisar a efetividade das pesquisas das duas universidades pesquisadas. Nesse sentido, o diferencial da comparação deste estudo tem como premissa destacar o desenvolvimento da tecnológica UTFPR quando comparada com uma universidade clássica, a UFABC, quanto à eficácia de seus modelos.

Foi encontrada uma patente de inovação da UTFPR em que foi realizada a transferência de tecnologia. Ela possui o número PI 1004385-3 A2 e tem como título Comunicação táctil para todo público: sistema Braile usando verniz relevo acrílico de secagem ultravioleta $(U V)$, impresso junto com textos e imagens em tinta, ausência de microfuros. Essa patente de invenção está classificada pelo IPC nas áreas de operações de processamento e transporte. Sua utilização tem como objetivo a inclusão e acessibilidade, que favorecem a educação, a capacitação profissional, a convivência e o relacionamento entre as pessoas deficientes visuais, que representam 6,8\% da população brasileira (INSTITUTO NACIONAL DE PROPRIEDADE INTELECTUAL, 2018).

Para a clássica UFABC, foram encontradas duas patentes em que houve transferência de tecnologia. A primeira tem o número BR 102014009510-1 e o título Compósitos elastômeros de polidimetilsiloxano com sistema cromotropicos de complexos inorgânicos termosolvatocrômico de metais de transição. A segunda tem o número BR 102014009699-0 e o título é Composto de silicone monocomponente, de alta estabilidade, reticulado por poliadição catalisada com platina. Ambas as patentes são classificadas pelo IPC na área 
tecnológica de operação de processamento, com subárea de conformação e produtos em camadas que contenham essencialmente metal.

A pesquisa aponta a dificuldade das duas IES de transferir tecnologia ao setor produtivo por meio das patentes de invenção. Nesse sentido, enfatiza-se a importância de modelos de gestão que sejam eficientes, menos burocráticos no acompanhamento do ritmo das inovações advindas do setor produtivo.

Para Thomas, Davyt e Dagnino (1997), a inovação não é gerada no vácuo, e sim através de processos cumulativos nos quais as trajetórias, mais do que tentativas isoladas, explicam o sucesso ou o fracasso. Até o final da década de 1970, na realidade latino-americana, o vinculacionismo, uma forma da geração de laços com a produção sob a responsabilidade das universidades de pesquisa e transferência, era adotada para que os resultados das pesquisas científicas e tecnológicas chegassem aos potenciais usuários. O modelo regional divergia da experiência de países desenvolvidos e, no teste do tempo, mostrou-se fracassado (DAGNINO; THOMAS, 2001; DAGNINO; GOMES; THOMAS, 2011).

Dagnino (2003) questiona a forma de parcerias adotada pelas universidades brasileiras com os setores produtivos, baseando-se em um modelo denominado de ofertista linear ou linear (science push), em que a pesquisa surge dentro da universidade e é oferecida para o mercado. O autor orienta a substituição do modelo atual para um modelo linear reverso (demand pull) orientado às demandas empresariais, criando um ambiente de colaboração efetivo entre as universidades e o mercado.

Na segunda metade da década de 1970, uma nova onda vinculacionista ligada com avanços da teoria da inovação (incubadoras de empresas, parques e polos tecnológicos, escritórios de patentes etc.) aconteceu na América Latina. Nesta onda neovinculacionista, ocorreu a transdução de fatos estilizados e teorizações de experiências de países desenvolvidos. Apesar dos avanços, a onda não refletiu as condições ofertistas do modelo linear de inovação (DAGNINO; THOMAS, 2001; DAGNINO; GOMES; THOMAS, 2011).

Uma das formas de minimizar a baixa transferência de tecnologia é buscando mudanças nos cursos de pós-graduação, trazendo problemas específicos dos setores produtivos e compartilhando-os com os pesquisadores da universidade. Em contrapartida, a universidade poderá transpor o ambiente acadêmico e realizar partes da sua pesquisa dentro das empresas, utilizando e compartilhando laboratórios, processos, e minimizando a distância entre a pesquisa básica e a aplicada. Nesse contexto, as duas IES estudadas têm propostas de cursos de mestrado e doutorado acadêmicos industriais, alguns em andamento. 
Gibbons et al. (1994) e Gibbons (2000) apresentam interfaces de produção de conhecimento das universidades americanas que influenciaram o modelo das universidades brasileiras:

a) o modo 1 de produção está centrado na pesquisa básica, institucionalizado em grandes universidades e vinculado com um dever coletivo e individual para o saber científico;

b) o modo 2 de produção é focado na pesquisa aplicada e as parcerias têm aderência com a ideia da hélice tripla.

Notadamente, a UFABC tem sua pesquisa centrada no modo 1, enquanto a UTFPR, que em tese deveria operar no modo 2 , de acordo com os resultados obtidos no presente estudo, também tem a produção do conhecimento derivada para o modo 1 .

Embora recaia sobre as universidades a função de inovar, ainda se percebe o dilema entre ser a torre de marfim e a busca da inovação tecnológica. Brito Cruz (2010) aduz que a universidade gera ideias importantes, mas tem e não pode aceitar a responsabilidade de produzir soluções para todos os problemas nacionais. Para Spatti (2017), ao comparar as principais estratégias e mecanismos de fomento implementados por três universidades públicas paulistas, mostra que, mesmo estando em suas agendas a necessidade de fortalecer a inovação, a pesquisa e o desenvolvimento tecnológico em parceria com empresas, faltam metodologias estruturadas de valoração das estratégias e instrumentos de fomento utilizados pelas universidades. Rapini (2007), investigando a base de dados do Diretório dos Grupos de Pesquisa do CNPq, evidencia a necessidade de um maior estreitamento nas relações da universidade com as empresas. Inobstante, os relacionamentos historicamente foram assentados em demanda pouco sofisticada por insumos acadêmicos. $\mathrm{O}$ foco do relacionamento sempre foi pequenas melhorias ou adaptações produzidas em pesquisas científicas e na transferência de tecnologia (RAPINI; RIGHI, 2005).

Para sobreviver, a universidade do século XXI está sujeita à sua capacidade de empreender, diversificar suas fontes de renda e financiamento, e isso depende de seu potencial de inovação e parceria com empresas.

\section{Considerações finais}

Com o objetivo de comparar os dois modelos de universidades - clássico e tecnológico - esta pesquisa utilizou duas variáveis definidas pela RUTyP como características de UTs: inovação e desenvolvimento e transferência de tecnologia. O caminho trilhado para a consecução do objetivo proposto foi o levantamento de dados cadastrados na Plataforma Lattes e concessões de patentes pelo INPI para a tecnológica UTFPR e para a clássica UFABC. 
Tendo em vista que as duas universidades são bastante jovens, quando se analisam as características da inovação da UTFPR, considerando apenas patentes de invenção concedidas e homologadas pelo INPI, há grande distanciamento da UTFPR em relação à UFABC, pois aquela conseguiu patentear mais inventos do que a clássica UFABC.

Nesse cenário, os dados apontam a área de necessidades humanas, com destaque para as áreas de ciências agrárias, com maior proporção de inventos. A UTFPR possui 13 campi espalhados pelo Estado do Paraná, alcançando o interior do estado, que possui sua principal economia no agronegócio, que hoje é responsável por 30\% do Produto Interno Bruto (PIB) do Estado. Destaca-se que as patentes até aqui concedidas para a UTFPR não estão ligadas às áreas de engenharia e tecnologia, como objetiva sua existência como universidade. A área de física (instrumentalização) é segunda maior área de patentes concedidas.

Para a UFABC, considerando patentes homologadas, mas não concedidas, sobressai a área de ciências exatas e da terra, com destaque para inventos na área de química orgânica, inorgânica e materiais.

Os resultados apresentados demostram que a tecnológica UTFPR possui capacidade de inovar, mas ainda não desponta como diferencial na área de engenharia e tecnologia em comparação à clássica UFABC.

Quando se trata de transferência de tecnologia para o setor produtivo, ainda falta integração com o setor produtivo para transferir os benefícios do invento e gerar emprego e renda para sociedade, o que denota que seu modelo de UT ainda precisa de consolidação.

Os dados cadastrados na Plataforma Lattes demostram potencial de inovação ainda reprimido por falta de interesse do pesquisador em legalizar a patente ou por incentivo das agências de inovação em criar ações para regularizar os registros da Plataforma Lattes que ainda não foram legalizados.

Este estudo é, portanto, indicador de outras possibilidades de pesquisas, outros dados como: empreendedorismo, parques tecnológicos e cidades do conhecimento, responsabilidade social e ambiental. A ligação com os setores produtivos, definidos pela RUTyP, pode ser considerada para comparação entre as IES. 


\section{Referências}

AGRESTI, A.; KATERI, M. Categorical data analysis. Berlin: Springer, 2011.

ALMEIDA, A. M. F.; ERNICA, M. Inclusão e segmentação social no ensino superior público no Estado de São Paulo (1990-2012). Revista Educação \& Sociedade, Campinas, v. 36, n. 130, p. 63-83, 2015. Disponível em: https://www.scielo.br/pdf/es/v36n130/0101-7330-es-36130-00063.pdf. Acesso em: 18 jul. 2019.

BARBOSA, D. B. Direito da inovação: comentários à Lei no 10.973/2004: Lei federal da inovação. Rio de Janeiro: Lúmen Júris, 2006.

BARREYRO, G. B.; AURELIANO, A. F. Características dos ingressantes de universidades públicas do Estado de São Paulo: novos campi, velhas desigualdades? Educere et Educare, Cascavel, v. 5, n. 10, 2010.Disponível em: http://erevista.unioeste.br/index.php/educereeteducare/article/view/5090/4027. Acesso em: 18 jul. 2019.

BERNI, J. C. A. et al. Interação universidade-empresa para a inovação e a transferência de tecnologia. Revista Gestão Universitária na América Latina, Florianópolis, v. 8, n. 2, p. 258-277, 2015. Disponível em: https://periodicos.ufsc.br/index.php/gual/article/view/19834535.2015v8n2p258. Acesso em: 18 jul. 2019.

BICALHO, L. M.; FERREIRA, M. A. T. Indicadores de produção de conhecimento tecnológico na universidade. E-Gov: Portal de e-governo, inclusão digital e sociedade do conhecimento. Florianópolis: Observatório do Governo, 2010. Disponível em:

https://egov.ufsc.br/portal/conteudo/indicadores-de-produ\%C3\%A7\%C3\%A3o-deconhecimento-tecnol\%C3\%B3gico-na-universidade. Acesso em: 18 jul. 2019.

BRASIL. Decreto $\mathrm{n}^{\circ} 2.208$, de 17 de abril de 1997. Regulamenta o $\S 2^{\circ}$ do art. 36 e os arts. 39 a 42 da Lei n. ${ }^{\circ} 9.394$, de 20 de dezembro de 1996, que estabelece as diretrizes e bases da educação nacional. Diário Oficial da União, Brasília, DF, seção 1, n. 74, p. 7760-7761, 18 abr. 1997. Disponível em:

https://pesquisa.in.gov.br/imprensa/jsp/visualiza/index.jsp?data=18/04/1997\&jornal=1\&pagin $\underline{\mathrm{a}=4 \& \text { totalArquivos }=80 .}$. Acesso em: 18 jul. 2019.

BRASIL. Lei $\mathrm{n}^{\mathrm{o}}$ 11.145, de 26 de julho de 2005. Institui a Fundação Universidade Federal do ABC - UFABC e dá outras providências. Diário Oficial da União,Brasília, DF, seção 1, n. 143, p. 1-2, 27 jul. 2005a. Disponível em:

https://pesquisa.in.gov.br/imprensa/jsp/visualiza/index.jsp?data=27/07/2005\&jornal=1\&pagin a=1\&totalArquivos=96. Acesso em: 18 jul. 2019.

BRASIL. Lei $\mathrm{n}^{\mathrm{o}}$ 11.184, 07 de outubro de 2005. Dispõe sobre a transformação do Centro Federal de Educação Tecnológica do Paraná em Universidade Tecnológica Federal do Paraná e dá outras providências. Diário Oficial da União, Brasília, DF, seção 1, n. 195, p. 1-2, 10 out. 2005b. Disponível em:

https://pesquisa.in.gov.br/imprensa/jsp/visualiza/index.jsp?jornal=1\&pagina $=1 \&$ data $=10 / 10 / 2$ 005. Acesso em: 18 jul. 2019. 
BRASIL. Lei de Diretrizes e Bases da Educação Nacional. Brasília: Senado Federal, Coordenação de Edições Técnicas, 2005c. Disponível em: https://www2.senado.leg.br/bdsf/bitstream/handle/id/70320/65.pdf. Acesso em: 18 jul. 2019.

BRASIL. Ministério da Ciência, Tecnologia e Inovação. Relatório Formict 2017 (ano base 2016). Brasília: MCTI, 2017. Disponível em: http://www.profnit.org.br/wpcontent/uploads/2017/08/Formict-2016-Encontro-Internacional-PROFINITpptx.pdf. Acesso em: 18 jul. 2019.

BRITO CRUZ, C. H. Ciência, tecnologia e inovação no Brasil: desafios para o período 2011 a 2015. Revista Interesse Nacional, São Paulo, jul. 2010. Disponível em:

http://interessenacional.com.br/2010/07/01/ciencia-tecnologia-e-inovacao-no-brasil-desafiospara-o-periodo-2011-a-2015/. Acesso em: 18 jul. 2019.

CAPELLE, K. The Federal University of ABC: pioneering research education in Brazil. Universidade Federal do ABC - Artigos. São Paulo, 15 mar. 2016. Disponível em:

http://www.ufabc.edu.br/artigos/the-federal-university-of-abc-pioneering-research-educationin-brazil-904. Acesso em: 18 jul. 2019.

CARDOSO, O. N. P.; MACHADO, R. T. M. Gestão do conhecimento usando data mining: estudo de caso na Universidade Federal de Lavras. Revista de Administração Pública, Rio de Janeiro, v. 42, n. 3, p. 495-528, 2008. Disponível em:

https://www.scielo.br/j/rap/a/4ScBD9DkFprnH7MFyKC3ydv/?lang=pt. Acesso em: 18 jul. 2019.

CLOSS, L. et al. Intervenientes na transferência de tecnologia universidade-empresa: o caso PUCRS. Revista de Administração Contemporânea, Curitiba, v. 16, n. 1, p. 59-78, 2012. Disponível em:

https://www.scielo.br/j/rac/a/JcwBJfHpQnMTLWPskNMSMMD/abstract/?lang=pt. Acesso em: 18 jul. 2019.

CLOSS, L. Q.; FERREIRA, G. C. A transferência de tecnologia universidade-empresa no contexto brasileiro: uma revisão de estudos científicos publicados entre os anos 2005 e 2009 . Gestão e Produção, São Carlos, v. 19, n. 2, p. 419-432, 2012. Disponível em:

https://www.scielo.br/j/gp/a/Z4Xqfg7djc7KfrgBcmdfLjF/?lang=pt. Acesso em: 18 jul. 2019.

CUNHA, L. A. A universidade reformada: o golpe de 1964 e a modernização do ensino superior. Rio de Janeiro: Francisco Alves, 1982.

CYSNE, M. do R. de F. P. Transferência de tecnologia entre a universidade e a indústria. Encontros Bibli, Florianópolis, v. 10, n. 20, p. 54-74, 2005. Disponível em: https://periodicos.ufsc.br/index.php/eb/article/view/1518-2924.2005v10n20p54. Acesso em: 18 jul. 2019.

DAGNINO, R. A relação universidade-empresa no Brasil e o "argumento da hélice tripla". Revista Brasileira de Inovação, Campinas, v. 2, n. 2, p. 267-307, 2003. Disponível em: https://periodicos.sbu.unicamp.br/ojs/index.php/rbi/article/view/8648874. Acesso em: 18 jul. 2019. 
DAGNINO, R.; GOMES, E. J.; THOMAS, H. Racionalidades da interação universidadeempresa na América Latina (1955-1995). In: DAGNINO, R.; THOMAS, H. (org.). A pesquisa universitária na América Latina e a vinculação universidade-empresa. Chapecó: Argos, 2011. p. 37-82.

DAGNINO, R.; THOMAS, H. Planejamento e políticas públicas de inovação: em direção a um marco de referência latino-americano. Planejamento e Políticas Públicas, Brasília, n. 23, p. 205-231, 2001. Disponível em: https://www.ipea.gov.br/ppp/index.php/PPP/article/view/76. Acesso em: 18 jul. 2019.

DELORS, J. et al. Educação: um tesouro a descobrir - relatório para a UNESCO da Comissão Internacional sobre Educação para o século XXI. Paris: Unesco, 2010. Disponível em: https://unesdoc.unesco.org/ark:/48223/pf0000109590_por. Acesso em: 18 jul. 2019.

ETZKOWITZ, H.; ZHOU, C. Hélice tríplice: inovação e empreendedorismo universidadeindústria-governo. Estudos Avançados, São Paulo, v. 31, n. 90, p. 23-48, 2017. Disponível em: https://www.scielo.br/j/ea/a/4gMzWdcjVXCMp5XyNbGYDMQ/?lang=pt. Acesso em: 18 jul. 2019.

GIBBONS, M. et al. The new production of knowledge: the dynamics of science and research in contemporary societies. London: SAGE Publications, 1994.

GIBBONS, M. The new production of knowledge: some policy implications for government. In: KRAAK, A. (ed.). Changing modes: new knowledge production and its implications for higher education in South Africa. Pretoria: HSRC, 2000. p. 39-55.

INSTITUTO NACIONAL DE PROPRIEDADE INTELECTUAL. Classificação

Internacional de Patentes. Brasília, 2018. Disponível em:

http://www.inpi.gov.br/sobre/estatisticas/arquivos/pagina-inicial/indicadores-de-propriedadeindustrial-2018_versao_portal.pdf. Acesso em: 18 jul. 2019.

LANE, J. Let's make science metrics more scientific. Nature, London, v. 464, p. 488-489, 2010. Disponível em: https://www.nature.com/articles/464488a. Acesso em: 18 jul. 2019.

MOURA, A. M. M. de; ROZADOS, H. B. F.; CAREGNATO, S. E. Interações entre ciência e tecnologia: análise da produção intelectual dos pesquisadores-inventores da primeira cartapatente da UFRGS. Encontros Bibli, Florianópolis, v. 11, n. 22, p. 1-15, 2006. Disponível em: https://periodicos.ufsc.br/index.php/eb/article/view/1518-2924.2006v11n22p1. Acesso em: 18 jul. 2019.

OLIVEIRA, R. M. de; VELHO, L. M. L. S. Patentes acadêmicas no Brasil: uma análise sobre as universidades públicas paulistas e seus inventores. Parcerias Estratégicas, Brasília, DF, v. 14, n. 29, p. 173-200, 2009. Disponível em:

http://seer.cgee.org.br/index.php/parcerias_estrategicas/article/view/355. Acesso em: 18 jul. 2019.

PILATTI, L. A.; LIEVORE, C. Redes de universidades: o caso da RUTyP. Educación

Superior y Sociedad, Caracas, v. 28, n. 18, p. 127-154, 2017. Disponível em:

https://www.iesalc.unesco.org/ess/index.php/ess3/article/view/87. Acesso em: 18 jul. 2019. 
PILATTI, L. A.; LIEVORE, C. Universidades tecnológicas: o que induziu esse modelo universitário no Brasil. Revista Brasileira de Ensino de Ciência e Tecnologia, Ponta Grossa, v. 11, n. 2, p. 582-613, maio/ago. 2018. Disponível em: https://periodicos.utfpr.edu.br/rbect/article/view/8471. Acesso em: 18 jul. 2019.

RANKING Universitário Folha 2018. São Paulo, Folha de S.Paulo, 2018. Disponível em: https://ruf.folha.uol.com.br/2018/ranking-de-universidades/. Acesso em: 18 jul. 2019.

RAPINI, M. S. Interação universidade-empresa no Brasil: evidências do Diretório dos Grupos de Pesquisa do CNPq. Estudos Econômicos, São Paulo, v. 37, n. 1, p. 211-233, 2007. Disponível em: https://www.revistas.usp.br/ee/article/view/35902. Acesso em: 18 jul. 2019.

RAPINI, M. S.; RIGHI, H. M. Interação universidade-empresa no Brasil em 2002 e 2004: uma aproximação a partir dos grupos de pesquisa do CNPq. In: ENCONTRO NACIONAL DE ECONOMIA, 33., 2005, Natal. Anais [...]. Rio de Janeiro: ANPEC, 2005. Disponível em: http://www.anpec.org.br/encontro2005/artigos/A05A105.pdf. Acesso em: 18 jul. 2019.

SANTOS, M. E. R. dos; ROSSI, A. L. Projeto "Estímulo à criação e consolidação de núcleos de propriedade intelectual e transferência de tecnologia em universidades brasileiras" - relatório final da etapa - mapeamento das instituições. Porto Alegre, 2002. Disponível em: https://www.redetec.org.br/wp-content/uploads/2015/02/Relatrio-FinalProjeto-Ncleos-Definitivo-1.pdf. Acesso em: 18 jul. 2019.

SCARTASSINI, V. B. Patentes brasileiras e patentes concedidas no Brasil na área da Química Orgânica indexadas na Base Derwent Innovation Index (DII) no período de 2004 a 2015. 2015. Monografia (Graduação em Biblioteconomia) - Universidade Federal do Rio Grande do Sul, Porto Alegre, 2015. Disponível em: https://lume.ufrgs.br/handle/10183/134822?locale-attribute=pt_BR. Acesso em: 18 jul. 2019.

SILVA, E. A. S. A. de; KOVALESKI, J. L. Cooperação universidade-indústria: o estudo de caso do Centro de Inovação Tecnológica de Compiégne-França. In: SEMINÁRIO LATINOIBEROAMERICANO DE GESTIÓN TECNOLÓGICA, 13., 2009. Anais [...]. Cartagenas de Indias: ALTEC, 2009. Disponível em:

https://www.researchgate.net/publication/266878322_cooperacao_universidadeindustria_o_es tudo_de_caso_do_centro_de_inovacao_tecnologica_de_compiegne-franca. Acesso em: 18 jul. 2019.

SILVA, J. G. S. F.; BORSCHIVER, S. Critérios para avaliação dos sistemas patentários. Revista da ABPI, Rio de Janeiro, n. 98, p. 30-41, 2009.

SILVEIRA, Z. S. da; BIANCHETTI, L. Universidade moderna: dos interesses do Estadonação às conveniências do mercado. Revista Brasileira de Educação, Rio de Janeiro, v. 21, n. 64, p. 79-99, 2016. Disponível em:

https://www.scielo.br/j/rbedu/a/5nwmMdVFqY3SGtHJBSL6PYj/?lang=pt. Acesso em: 18 jul. 2019. 
SPATTI, A. C. Interação universidade-empresa: um estudo crítico comparado das três universidades públicas paulistas. 2017. Dissertação (Mestrado em Ciências Humanas e Sociais Aplicadas) - Universidade de Campinas, Limeira, 2017. Disponível em:

http://repositorio.unicamp.br/jspui/handle/REPOSIP/325337. Acesso em: 18 jul. 2019.

THE WORLD UNIVERSITY RANKING. Latin American Ranking. London, 2018. Disponível em: https://www.timeshighereducation.com/world-university-rankings/2018/latinamerica-university-rankings\#!/page/0/length/25/sort_by/rank/sort_order/asc/cols/undefined. Acesso em: 18 jul. 2019.

THOMAS, H.; DAVYT, A.; DAGNINO, R. Racionalidades de la interacción universidadempresa en América Latina (1955-1995). Revista Espacios, Caracas, Venezuela, v. 18, n. 1, 1997. Disponível em: http://www.revistaespacios.com/a97v18n01/30971801.html. Acesso em: 18 jul. 2019.

UNIVERSIDADE TECNOLÓGICA FEDERAL DO PARANÁ (UTFPR). Projeto PolíticoPedagógico Institucional (PPI). Curitiba: UTFPR, 2007. Disponível em: http://www2.td.utfpr.edu.br/eng_civil/pdf/ppi.pdf. Acesso em: 18 jul. 2019. 